\title{
Lean-seafood intake increases urinary iodine concentrations and plasma selenium levels: a randomized controlled trial with crossover design
}

\author{
Jannike Øyen ${ }^{1}\left[\right.$ · Eli Kristin Aadland ${ }^{1,2} \cdot$ Bjørn Liaset $^{1} \cdot$ Even Fjære $^{1} \cdot$ Lisbeth Dahl $^{1} \cdot$ Lise Madsen $^{1,3}$
}

Received: 30 January 2020 / Accepted: 10 August 2020 / Published online: 27 August 2020

(c) The Author(s) 2020

\begin{abstract}
Purpose Iodine deficiency due to insufficient nutritional intake is a public health challenge in several European countries, including Norway. Lean-seafood has a high iodine and arsenic (As) content and is a good source of selenium (Se). Evidence of a direct effect of increased intake of lean-seafood on iodine status is limited. The main aims were to determine the iodine status at baseline and to investigate possible dietary effects on urinary iodine concentration (UIC) after intervention with lean-seafood versus non-seafood. Plasma Se, and plasma and urinary As concentrations were also measured.

Methods A randomized controlled crossover study comprising two 4 weeks experimental periods with two balanced diets varied in main proteins (60\% of total dietary proteins) of lean-seafood and non-seafood, separated by a 5 week washout period.

Results Twenty participants ( 7 males, 13 females) were included and the mean \pm SD age was $50.6 \pm 15.3$ years for all participants. Fasting UIC was median $(25$ th, 75 th percentile) $70(38,110)$ and $79(49,94) \mu \mathrm{g} / \mathrm{L}$ in the lean-seafood and non-seafood intervention at baseline, respectively. UIC increased after 4 weeks of the lean-seafood intervention to $135(110,278) \mu \mathrm{g} / \mathrm{L}$, but not after the non-seafood intervention $[58(33,91) \mu \mathrm{g} / \mathrm{L}](P$ diet-effect $<0.001)$. Fasting plasma Se increased in the lean-seafood intervention and decreased in the non-seafood intervention $(P$ diet-effect $=0.001)$. Fasting urinary and plasma As increased in the lean-seafood intervention and was unchanged in the non-seafood intervention $(P$ diet-effect $<0.001)$. Conclusion The participant's UIC was below the recommended median $(100 \mu \mathrm{g} / \mathrm{L})$ at baseline, but increased sufficiently after a 4 week intervention with lean-seafood.
\end{abstract}

Keywords Arsenic $\cdot$ Iodine $\cdot$ Lean-seafood $\cdot \mathrm{RCT} \cdot$ Selenium

Electronic supplementary material The online version of this article (https://doi.org/10.1007/s00394-020-02366-2) contains supplementary material, which is available to authorized users.

Jannike Øyen

jannike.oyen@hi.no

1 Institute of Marine Research, P.O. Box 1870 Nordnes, 5817 Bergen, Norway

2 Department of Sport, Food and Natural Sciences, Western Norway University of Applied Science, Bergen, Norway

3 Department of Biology, University of Copenhagen, Copenhagen, Denmark

\section{Introduction}

Iodine is essential for thyroid hormone production [1]. Suboptimal iodine status is a public health concern worldwide, and despite efforts to increase the dietary iodine intake, Europe is still the continent with the highest prevalence of iodine deficiency [2]. This is a particular concern for women that are pregnant and/or at childbearing age [3-7].

Dietary sources of iodine are limited. Hence, to cope with iodine insufficiency, iodized salt programmes are recommended [4, 8]. Such programmes have a high impact globally, but several European countries have not followed this strategy. The impact of iodized salt in Norway is limited as the amount of iodine in the iodized salt is low ( $5 \mathrm{mg}$ iodine $/ \mathrm{kg}$ salt), and the food industry is not allowed to use iodized salt. However, the cow feed has been fortified with iodine since the 1950s. Thus, milk and dairy 
products are the major sources of iodine in Norway [9, 10], and contributes with about $55 \%$ of the iodine intake [11]. Seawater fish and seafood are the food items where iodine is occurring at the highest concentrations $[10,12]$. Although the concentration of iodine is higher in seafood than milk and dairy products there is lack of associations between intake of seafood and adequate UIC in Danish and Icelandic populations $[13,14]$. However, a direct effect of increased intake of lean-seafood on UIC has to our knowledge been demonstrated in one intervention study [15]. Unlike iodized salt, intake of lean-seafood will also provide other components. Lean-seafood contains undesirable substances such as $\mathrm{Hg}$ [16], but also essential nutrients, such as selenium (Se), B vitamins, trace elements and some long chain n-3 polyunsaturated fatty acids [17]. Additionally, lean fish also provide high quality marine proteins and taurine [18].

UIC in spot urine samples is the recommended method to assess iodine status by World Health Organization (WHO), United Nations children's fund (UNICEF) and Iodine Global Network (IGN). Importantly, however, UIC reflects the last $24 \mathrm{~h}$ of iodine intake. Hence, even if seafood is consumed 2-3 times a week as recommended, associations between seafood intake and UIC would necessarily be more difficult to reveal than associations with intake of items often consumed on a daily basis, such as milk and dairy. Thus, as lean-seafood is rarely consumed daily and UIC reflects the last day of iodine intake, the contribution of seafood for maintenance of sufficient iodine status may be underestimated in population-based studies.

To document the effect of lean-seafood on iodine status, we measured iodine in urine collected from participants in an intervention study, with a crossover design where leanseafood was consumed every day and intake of milk and dairy were restricted. As lean-seafood also is the main contributor of dietary arsenic (As) and represents an important source for Se, we concurrently measured plasma levels of Se and As, as well as urinary As.

\section{Materials and methods}

\section{Ethics statement}

The study was registered at www.ClinicalTrials.gov (NCT01708681) and performed in accordance with the ethical standards of the regional committee on human experimentation. The protocol, informed consent and advertisements were approved by the Regional Committee for Medical and Health Research Ethics West, Norway (Reference \# 2012/1084). All subjects signed a written informed consent.

\section{Study procedure and participants}

This study is based on a previous performed RCT with crossover design where the primary outcome was the change in fasting and postprandial lipids from pre- to post-intervention during the two intervention periods. Experimental design and recruitment of participants are earlier described by Aadland et al. [19]. The participants were recruited during October and November 2012. The 1st intervention period was from January to February 2013 and the 2nd intervention period from April to May 2013.

Recruitment of participants, inclusion/exclusion criteria and their physical and clinical characteristics have been described [19]. Briefly, healthy, non-smoking, male and female Caucasian subjects, 18-65 years old were recruited in the great area of Bergen, Norway.

Based on data obtained from a pre-study visit [19], 30 subjects were invited to participate and 27 subjects accepted to start. Of these, 20 subjects completed period one ( 7 men and 13 women) and 19 subjects ( 7 men and 12 women) completed both periods (Fig. 1). No adverse events were reported during or after the intervention.

\section{Outcome measures and power calculation}

The primary outcome in this RCT with crossover design was the change in fasting and postprandial lipids from pre- to post-intervention during the two intervention periods, and sample size was calculated based on the efficacy of fish protein to reduce plasma VLDL-TAG [19] and on the procedure described by Wellek and Blettner [20] for crossover design in clinical trials. A minimum of 16 subjects was needed to detect a treatment difference of $\sim 25-30 \%$ in plasma VLDLTAG at a probability level inferior to 0.05 and a power level corresponding to $80 \%$. The primary outcome in the present paper was UIC, and secondary outcomes were plasma levels of Se and As, as well as urinary As.

\section{Experimental design}

As described previously [19], a controlled, randomized crossover study comprising two 4 weeks experimental periods, separated by a 5 week washout period was performed (Fig. 2). Prior to study start, the subjects were randomly allocated to start with one of the two dietary interventions. Randomization was performed by placing 30 pieces of papers, each piece with one of the participant's identification number, and in an alternating order assigning the subjects to start with the lean-seafood or non-seafood diet by picking the paper pieces sequentially from the box. All participants were instructed to follow a diet in accordance with 


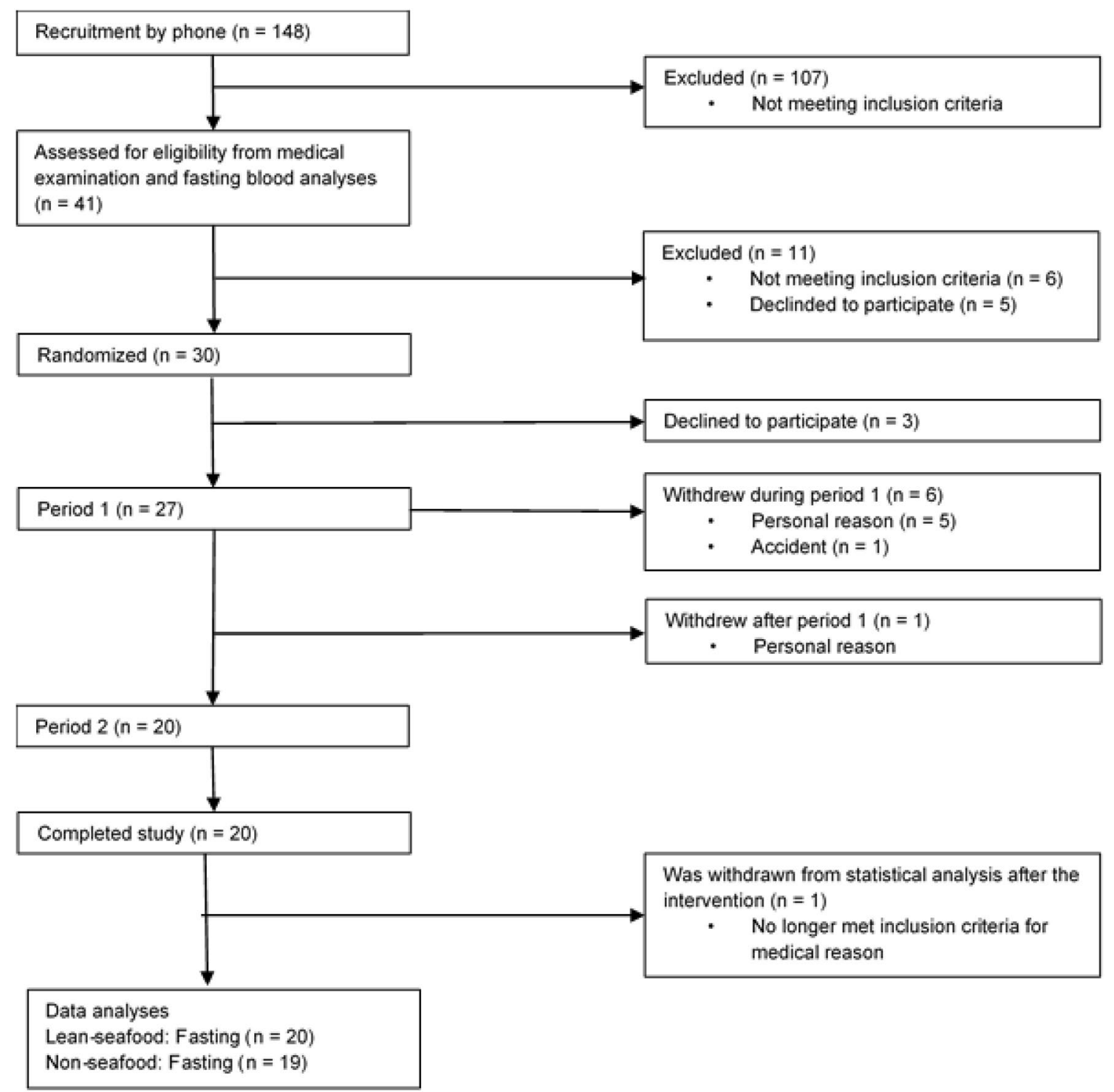

Fig. 1 Consolidated flow chart for recruitment, randomization, and data sampling from the study participants

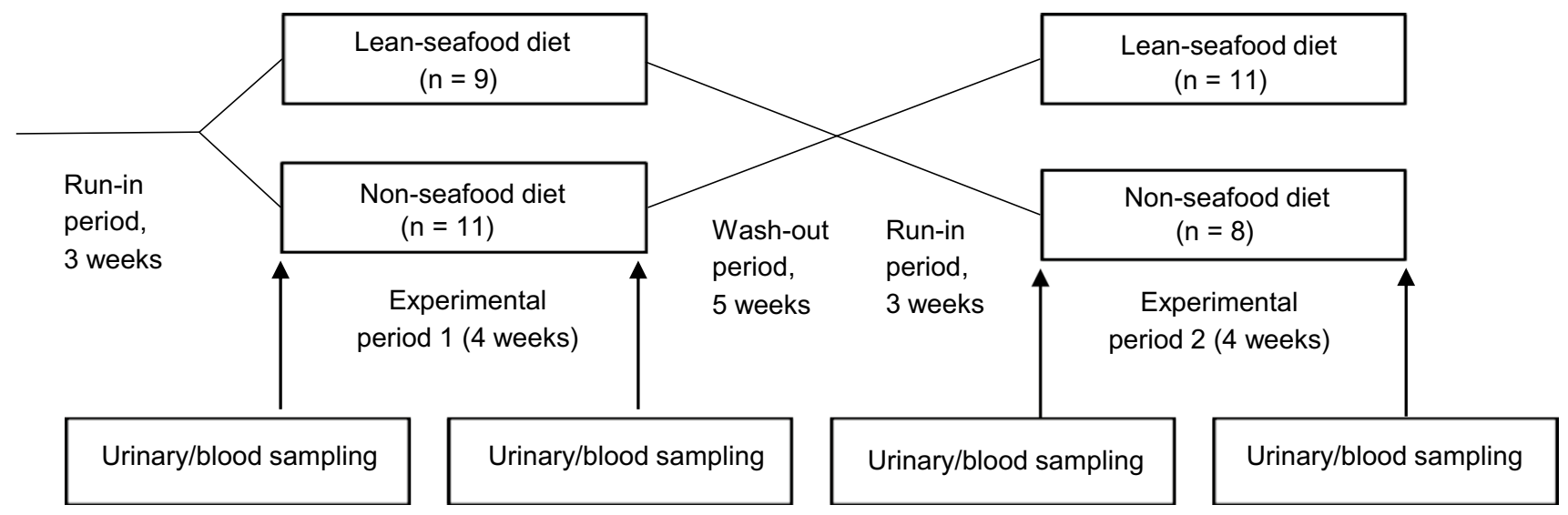

Fig. 2 The crossover study design 
the Norwegian dietary recommendations [21] for 3 weeks (run-in period), with additional specifications to include a maximum of one fatty fish (salmon, trout, mackerel or herring) meal per week prior both experiments periods. During the last week of the run-in period and washout periods and throughout both experimental periods, the participants were instructed to avoid alcohol, chocolate or candy, industrial baked cakes or cookies, fast food, probiotics, and fish or fish oil supplements. They were also instructed to maintain their normal physical activity level during the run-in, experimental and washout periods. Fourteen subjects (6 men and 8 women) assigned to the lean-seafood diet consisting of lunch- and dinner meals with the 1 st experimental period, whereas 13 subjects ( 4 men and 9 women) were assigned to a non-seafood diet. Compliance was assessed daily by an oral questionnaire. Only minor deviations occurred. Body mass was monitored and if necessary, dietary energy level adjusted to maintain a stable body weight $( \pm 2 \mathrm{~kg})$ in each experimental period.

\section{Diets}

The experimental diets were prepared to meet the Norwegian nutrition recommendations [21], and formulated to meet energy the individual energy requirements for each participant as calculated from the self-reported food frequency questionnaire (FFQ) and using both the International (Harris-Benedict equation) [22] and the Nordic energy requirement references [23]. Six energy levels were established for each diet $(7500,8300,9600,10,900,12,200$ and 13,500 kJ/ day). The experimental protein sources, covering $60 \%$ of total protein, the lean-seafood diet comprised cod, pollack, saithe and scallops, whereas the non-seafood diet comprised chicken breast filet without skin, lean beef, turkey breast filet without skin, pork, egg, low fat and skimmed milk (as ingredients in some of the meal recipes) and milk products (non-seafood diet). The remaining $40 \%$ of dietary protein was from vegetable and cereal sources. The experimental diets were balanced with equivalent amounts of dietary fibre, carbohydrates, protein, lipids, but not for cholesterol, which was higher for the non-seafood diet. Salt in both diets was restricted to a maximum of $5 \mathrm{~g}$ daily. Importantly, the participants were instructed to not drink milk during any of the interventions, and only small amounts of dairy products were included in the non-seafood diet. In the lean-seafood diet, the only dairy product was small amount of butter in the diets twice a week. To fulfil the Nordic recommendation for calcium and vitamin $\mathrm{D}$, the participants received $750 \mathrm{mg}$ calcium supplement during the lean-seafood intervention and $500 \mathrm{mg}$ calcium supplement during the nonseafood intervention. For vitamin D, the participants daily received Vitamin $\mathrm{D}_{3}(10 \mu \mathrm{g}$ or $400 \mathrm{IU})$ supplement during the lean-seafood intervention [23]. The two experimental diets were presented as 7 day rotating menus, and the composition of energy and nutrients was determined by the Norwegian Nutrient File database ("Kostholdsplanleggeren") as shown in Table 1. The amino acid and the fatty acid composition, and examples of 1 day menus have been published previously [19]. Results from the analyses of Se in the leanseafood and non-seafood intervention meals correspond to average 97 and $56 \mu \mathrm{g} / \mathrm{day}$, respectively. The corresponding figures for As were 1094 and $13 \mu \mathrm{g} /$ day, respectively.

The participants prepared breakfasts, evening meals and snacks at home using an approved food list adjusted to their experimental diet and energy level, whereas lunches were prepared at the Western Norway University of Applied Science and provided for the day after. During the weekdays, dinners were served at the Western Norway University of Applied Science, whereas weekend dinners were distributed on Fridays together with weekend and Monday lunches.

\section{Biochemical analyses}

Fasting morning spot urine was collected at day 1 and at the last day of each experimental period. The urine was aliquoted and stored at $-80{ }^{\circ} \mathrm{C}$ prior to analyses. Blood was drawn from the antecubital vein at the clinic after an overnight fast at the first and the last day of each experimental period and EDTA plasma was prepared and stored at $-80^{\circ} \mathrm{C}$.

Urinary iodine and As concentrations [24], Se in plasma, and Se and As from the intervention meals [25, 26] were determined by Inductive Coupled Plasma Mass

Table 1 Mean ${ }^{\text {a }}$ composition of the 7 day experimental diets

\begin{tabular}{lll}
\hline & Lean-seafood & Non-seafood \\
\hline Total energy (kJ) & $10,882 \pm 550$ & $10,900 \pm 452$ \\
Carbohydrates (\% of energy) & $52 \pm 1$ & $52 \pm 1$ \\
Lipids (\% of energy) & $29 \pm 1$ & $29 \pm 2$ \\
Protein (\% of energy) & $19 \pm 1$ & $19 \pm 1$ \\
PUFA (g) & $17 \pm 5$ & $17 \pm 5$ \\
MUFA (g) & $35 \pm 5$ & $35 \pm 8$ \\
SFA (g) & $25 \pm 8$ & $25 \pm 3$ \\
EPA+DHA (g) & 0.82 & $0.82^{\mathrm{b}}$ \\
Total fibre $(\mathrm{g})$ & $43 \pm 4$ & $43 \pm 4$ \\
Iodine ( $\mu \mathrm{g})$ & $828 \pm 167$ & $92 \pm 29$ \\
Se $(\mu \mathrm{g})$ & $113 \pm 18$ & $54 \pm 13$ \\
\hline
\end{tabular}

Data are mean $\pm \mathrm{SD}$

DHA docosahexaenoic acids, EPA eicosapentaenoic acid, MUFA monounsatured fatty acids, PUFA polyunsaturated fatty acids, SFA saturated fatty acids, $S e$ selenium

${ }^{a}$ Mean of the 7 day menu cycle for the $10,900 \mathrm{~kJ}$ diet, as determined by the Norwegian nutrient file database ("Kostholdsplanleggeren")

${ }^{\mathrm{b}}$ The non-seafood dinner meals were supplemented with $3.3 \mathrm{~g}$ cod liver oil, containing $0.28 \mathrm{~g}$ EPA and $0.42 \mathrm{~g}$ DHA 
Spectrometry (ICP-MS) by standardized procedures at Institute of Marine Research. For the determination of total Se and As in plasma, samples were diluted to a final volume of $10 \mathrm{ml}$ with deionized water. Prior to ICP-MS analyses [15], subsamples of $0.3 \mathrm{~g}$ were digested using $2.0 \mathrm{ml}$ concentrated nitric acid (Merck, Darmstadt, Germany) and $0.50 \mathrm{ml} \mathrm{30 \%}$ w/w hydrogen peroxide (Merck) in an Ethos Pro microwave system (Milestone, Sorisole, Italy). The technicians performing the analyses were blinded by giving the samples unique number codes.

\section{Statistical analyses}

Continuous variables are expressed as mean with standard deviation (SD), and median with 25 th, 75 th percentile. All residuals were normally disturbed, checked using histograms and normal probability $(\mathrm{Q}-\mathrm{Q})$ plots. The paired t test was used to compare variables within the intervention groups. Mixed-model linear regression analyses were used to analyse possible diet-effects on the outcomes from pre- to postintervention with the post-values as response and pre-values as covariate. The models were also adjusted for gender and/ or age, but did not differ from the unadjusted analyses (data not shown).

Two-tailed $p<0.05$ was considered statistically significant. Analyses were performed using the Statistical Package for the Social Sciences (SPSS ${ }^{\circledR}$ Statistics Version 26).

\section{Results}

\section{Characteristics of the participants}

The mean \pm SD age was $50.6 \pm 15.3$ years for all participants $(n=20), 49.7 \pm 18.6$ years for males and $51.0 \pm 14.1$ years for females. The average body weight and body mass index (BMI) was $86.3 \pm 9.1 \mathrm{~kg}$ and $26.4 \pm 3.0 \mathrm{~kg} / \mathrm{m}^{2}$ in male, and $70.3 \pm 7.0 \mathrm{~kg}$, and $25.3 \pm 3.0 \mathrm{~kg} / \mathrm{m}^{2}$ in female participants. Other characteristics of the participants have been published previously [19].

\section{Urinary iodine concentration}

Pre- and post-intervention results of UIC by median (25th, 75 th percentile) within and between the interventions are given in Table 2 and Fig. 3. Median (25th, 75th percentile) UIC was $70(38,110)$ and $79(49,94) \mu \mathrm{g} / \mathrm{L}$ in the lean-seafood and non-seafood intervention at baseline, respectively. 4 weeks of the lean-seafood intervention increased UIC to $135(110,278) \mu \mathrm{g} / \mathrm{L}(p<0.001)$, whereas UIC was not significantly changed after the non-seafood intervention [58 $(33,91) \mu \mathrm{g} / \mathrm{L}, p=0.077]$, but a significant diet-effect was observed $(p<0.001)$ (Table 2, Fig. 3). Six (30\%) of the participants in the lean-seafood intervention had UIC values $\geq 100 \mu \mathrm{g} / \mathrm{L}$ at baseline, and $18(90 \%)$ at post-intervention. The corresponding figures in the nonseafood intervention were $4(21 \%)$ at pre-intervention, and $3(16 \%)$ at post-intervention.

\section{Plasma selenium}

Pre- and post-intervention results of plasma Se by median (25th, 75th percentile) within and between the interventions are given in Table 2 and Fig. 4. Fasting plasma Se increased significantly from median (25th, 75 th percentile) $70(58,73) \mu \mathrm{g} / \mathrm{L}$ to $75(68,85) \mu \mathrm{g} / \mathrm{L}(p<0.001)$ in the lean-seafood intervention and decreased from $69(63,75)$ $\mu \mathrm{g} / \mathrm{L}$ to $67(60,70) \mu \mathrm{g} / \mathrm{L}(p=0.015)$ in the non-seafood intervention, and a significant diet-effect was observed $(p=0.001)$ (Table 2, Fig. 4).

Table 2 Urinary iodine and As concentrations and plasma Se and As concentrations in the subjects before and after 4 weeks interventions

\begin{tabular}{|c|c|c|c|c|c|c|c|c|c|}
\hline \multirow{3}{*}{$\begin{array}{l}\text { Biochemical } \\
\text { parameters }(\mu \mathrm{g} / \mathrm{L})\end{array}$} & \multicolumn{4}{|c|}{ Lean-seafood intervention $(n=20)$} & \multicolumn{5}{|c|}{ Non-seafood intervention $(n=19)$} \\
\hline & \multicolumn{2}{|c|}{ Pre } & \multicolumn{2}{|l|}{ Post } & \multicolumn{2}{|c|}{ Pre } & \multicolumn{3}{|l|}{ Post } \\
\hline & $N$ & $\begin{array}{l}\text { Median (25th, } \\
\text { 75th percentile) }\end{array}$ & $\begin{array}{l}\text { Median } \\
\text { (25th, 75th percentile) }\end{array}$ & $P^{\mathrm{a}}$ & $N$ & $\begin{array}{l}\text { Median (25th, } \\
75 \text { th percentile) }\end{array}$ & $\begin{array}{l}\text { Median (25th, } \\
75 \text { th percentile) }\end{array}$ & $P^{\mathrm{a}}$ & $P^{\mathrm{b}}$ \\
\hline UIC & 20 & $70(38,110)$ & $135(110,278)$ & $<0.001$ & 19 & $79(49,94)$ & $58(33,91)$ & 0.077 & $<0.001$ \\
\hline Plasma Se & 19 & $70(58,73)$ & $75(68,85)$ & $<0.001$ & 17 & $69(63,75)$ & $67(60,70)$ & 0.015 & 0.001 \\
\hline Urinary As & 20 & $62(21,180)$ & $495(300,740)$ & 0.002 & 19 & $48(13,96)$ & $7(5,10)$ & 0.059 & $<0.001$ \\
\hline Plasma As & 19 & $5(3,8)$ & $19(9,25)$ & 0.001 & 17 & $4(3,11)$ & $4(3,5)$ & 0.651 & $<0.001$ \\
\hline
\end{tabular}

As Arsenic, Se selenium, UIC urinary iodine concentration

${ }^{\text {a }} P$ for comparison within the intervention groups, paired sample $t$ test

${ }^{\mathrm{b}} P$ for comparison of diet effect between the intervention groups, mixed model regression analyses 


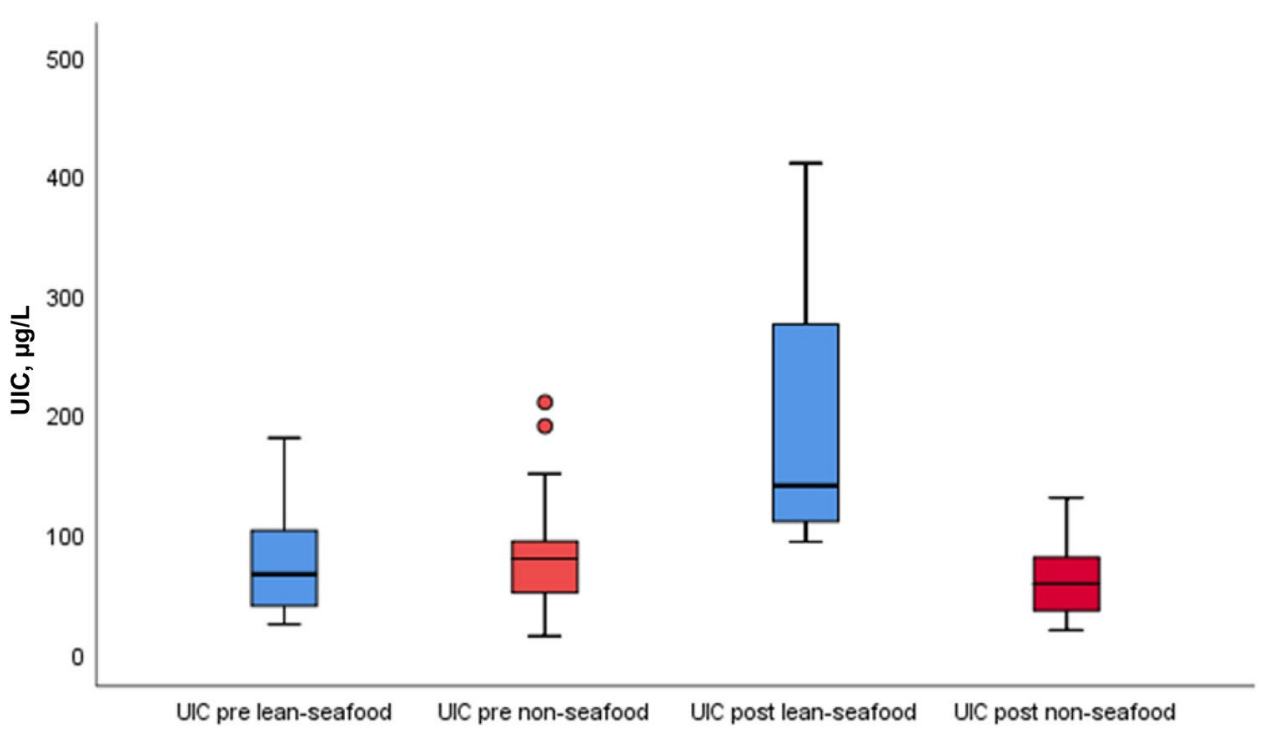

Fig. 3 Pre-and post-intervention results of the UIC in $\mu \mathrm{g} / \mathrm{L}$ within and between the lean-seafood $(n=20)$ and non-seafood $(n=19)$ interventions. The horizontal line through the box represents the median. The lower boundary of the box is the 25th percentile and the upper bounder is the 75 th percentile. The smallest and largest observed val- ues within the distribution are represented by the horizontal at either end of the box. Outliers are marked with circles. $P$ for comparison of diet-effect between the intervention groups, mixed model regression analyses $<0.001$. UIC urinary iodine concentration
Fig. 4 Pre-and post-intervention results of the plasma Se in $\mu \mathrm{g} / \mathrm{L}$ within and between the lean-seafood $(n=19)$ and nonseafood $(n=17)$ interventions. The horizontal line through the box represents the median. The lower boundary of the box is the 25 th percentile and the upper bounder is the 75 th percentile. The smallest and largest observed values within the distribution are represented by the horizontal at either end of the box. Outliers are marked with circles. $P$ for comparison of diet-effect between the intervention groups, mixed model regression analyses $=0.001$. Se selenium

\section{Urinary and plasma arsenic}

Pre- and post-intervention results of fasting urinary and plasma As by median (25th, 75th percentile) within and between the interventions are given in Table 2 and Fig. 5 and 6. Urinary As increased significantly from median (25th, 75th percentile) $62(21,180) \mu \mathrm{g} / \mathrm{L}$ to $495(300$, $740) \mu \mathrm{g} / \mathrm{L}(p=0.002)$ in the lean-seafood intervention and was unchanged in the non-seafood intervention [from 48 $(13,96) \mu \mathrm{g} / \mathrm{L}$ to $7(5,10) \mu \mathrm{g} / \mathrm{L}, p=0.059]$, but a significant diet-effect was observed $(p<0.001)$ (Table 2, Fig. 5).

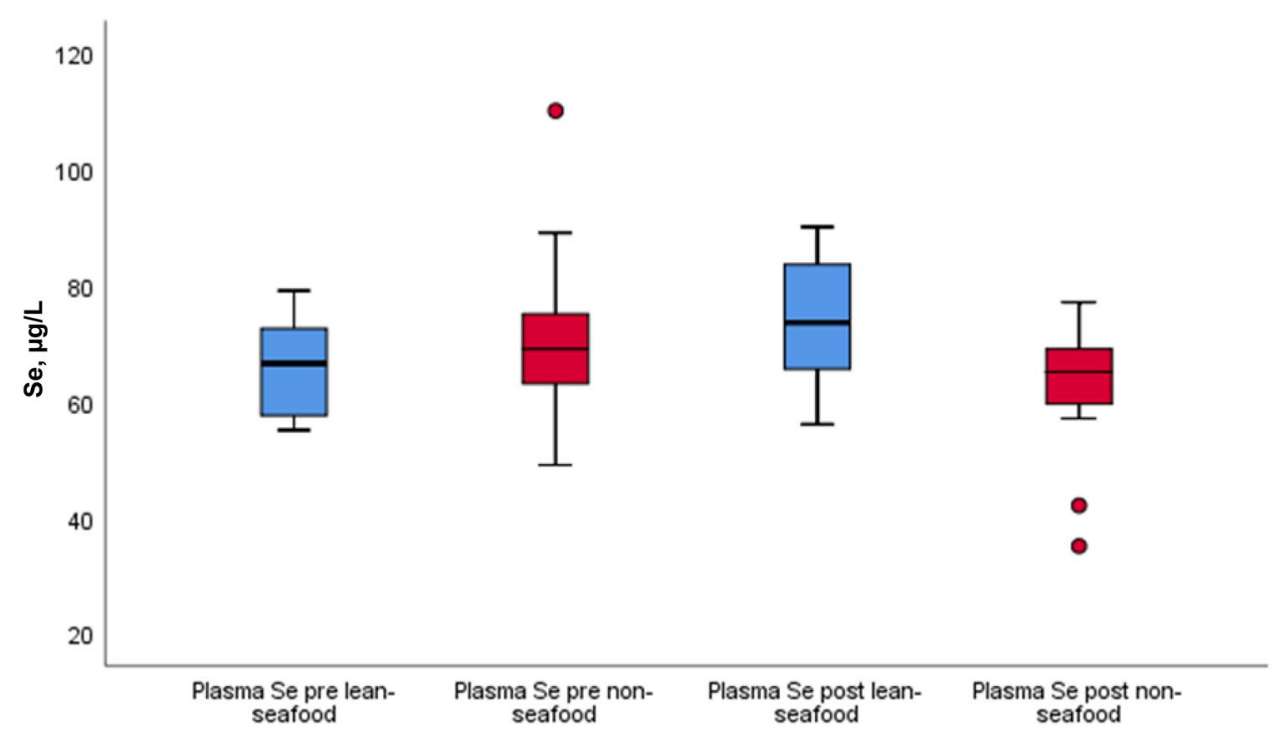

Plasma As increased significantly from median (25th, 75 th percentile $) 5(3,8) \mu \mathrm{g} / \mathrm{L}$ to $19(9,25) \mu \mathrm{g} / \mathrm{L}(p=0.001)$ in the lean-seafood intervention and was unchanged in the non-seafood intervention [from $4(3,11) \mu \mathrm{g} / \mathrm{L}$ to $4(3$, 5) $\mu \mathrm{g} / \mathrm{L}, p=0.651]$, but a significant diet-effect was observed $(p<0.001)$ (Table 2, Fig. 6). 


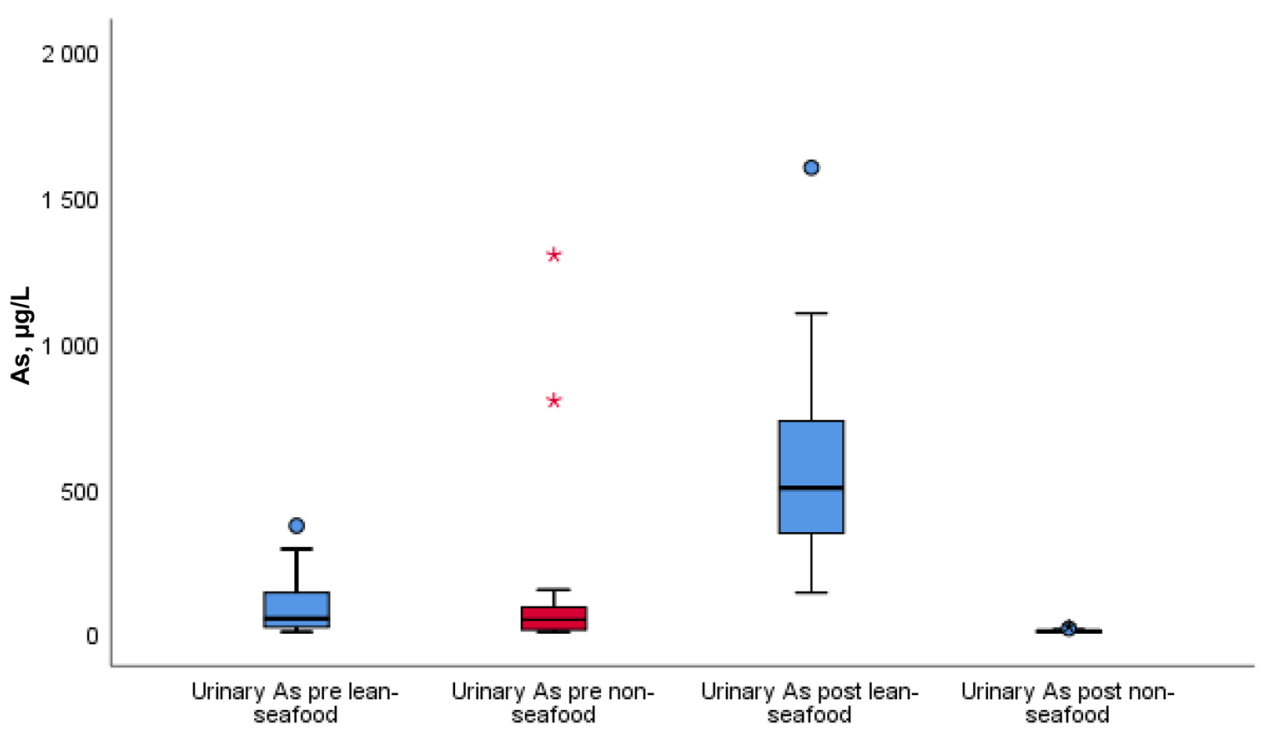

Fig. 5 Pre-and post-intervention results of the urinary As in $\mu \mathrm{g} / \mathrm{L}$ within and between the lean-seafood $(n=20)$ and non-seafood $(n=19)$ interventions. The horizontal line through the box represents the median. The lower boundary of the box is the 25th percentile and the upper bounder is the 75 th percentile. The smallest and largest observed values within the distribution are represented by the horizontal at either end of the box. Outliers are marked with circles or asterisk (extreme points). $P$ for comparison of diet-effect between the intervention groups, mixed model regression analyses $<0.001$. As arsenic

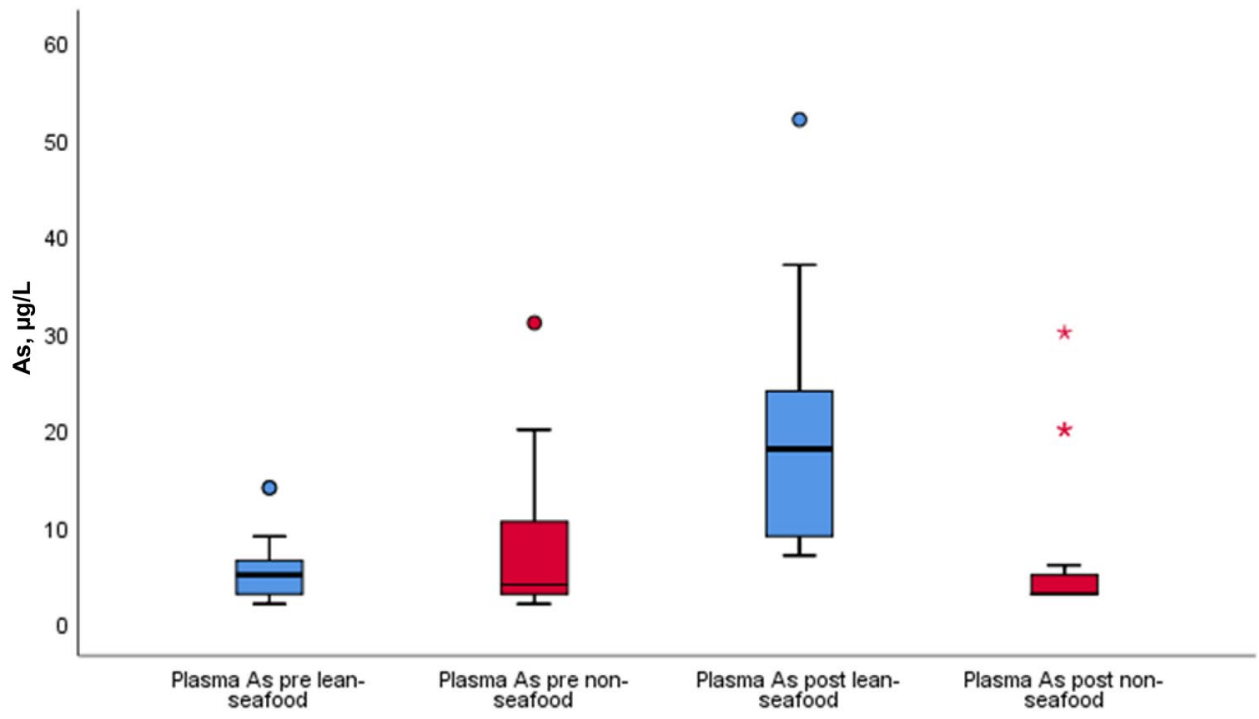

Fig. 6 Pre-and post-intervention results of the plasma As in $\mu \mathrm{g} / \mathrm{L}$ within and between the lean-seafood $(n=19)$ and non-seafood $(n=17)$ interventions. The horizontal line through the box represents the median. The lower boundary of the box is the 25 th percentile and the upper bounder is the 75th percentile. The smallest and

\section{Discussion}

Lean-seafood has the highest natural iodine content, but evidence of a direct impact of increased intake of leanseafood on UIC is limited. We therefore aimed to measure largest observed values within the distribution are represented by the horizontal at either end of the box. Outliers are marked with circles or asterisk (extreme points). $P$ for comparison of diet-effect between the intervention groups, mixed model regression analyses $<0.001$. As arsenic

UIC after intervention with lean-seafood and non-seafood in an intervention study with crossover design. The participant's UIC was below the recommended median at baseline, but after 4 weeks of the lean-seafood intervention median UIC was above $100 \mu \mathrm{g} / \mathrm{L}$. 
The present investigation demonstrated that a 28 day lean-seafood intervention increased median UIC by $65 \mu \mathrm{g} / \mathrm{L}$, whereas the UIC was unchanged after the non-seafood intervention. Lean-seafood is a well-known source of iodine, but to our knowledge, this is the second intervention study directly demonstrating an effect of intake of lean-seafood on UIC. In a Norwegian 14 day semi-controlled study by Molin et al. [15], 38 participants were randomized into four groups for daily portions of $150 \mathrm{~g}$ cod, salmon, blue mussels or potato (control). The participants in the cod and blue mussel groups increased significantly their UIC from median 80-220 $\mu \mathrm{g} / \mathrm{L}$ and $85-155 \mu \mathrm{g} / \mathrm{L}$, respectively, compared to the control group with unchanged UIC from pre- to post-intervention $(95 \mu \mathrm{g} / \mathrm{L})$. Increases in UIC have also been demonstrated with cow milk [27], seaweed [28], and supplements [29]. Given the high iodine levels in leanseafood, our result was expected. Further, the historically good iodine status in the Icelandic population has, at least in part, been attributed to a high intake of fish [30, 31]. Still, although seafood is suggested to contribute to iodine status, UIC has been associated with intake of milk and dairy, and not seafood, in population-based studies from for example Iceland [32], Norway [33, 34], and Italy [35]. Additional, in a Danish crossover study including a random sample of inhabitants living in Alborg and Copenhagen, estimated $24 \mathrm{~h}$ UIC increased with increased seafood intake in participants living in Alborg, but not in Copenhagen, whereas increased milk intake was associated with increased UIC in both cities. However, even though the intake of seafood was above $75 \mathrm{~g} / \mathrm{d}$ in the group of Alborg participants who consumed most, the UIC was inadequate (median $71 \mu \mathrm{g} / \mathrm{L}$ ), and adequate UIC was detected only in those living in Copenhagen who consumed more than two glasses of milk daily [14]. Unlike seafood, with a recommended intake of 2-3 times a week, milk and dairy are often consumed daily. As UIC reflects intake of iodine the last $24 \mathrm{~h}$, associations between seafood and UIC may be more difficult to detect, and therefore the overall contribution of seafood to iodine status may be underestimated.

At baseline, the median UIC was below $100 \mu \mathrm{g} / \mathrm{L}$ and hence, iodine status in the participants comprising 20 healthy adult Norwegians may be considered suboptimal. The number of participants is small, but our finding that about $70 \%$ of the participants had UIC below $100 \mu \mathrm{g} / \mathrm{L}$ at study start corroborate the suggestion that iodine deficiency or sub-optimal iodine status is a re-emerging condition in Norway. For instance, recent studies have reported median UIC of $68 \mu \mathrm{g} / \mathrm{L}$ [3] and $85 \mu \mathrm{g} / \mathrm{L}$ [36] in pregnant women, and $75 \mu \mathrm{g} / \mathrm{L}$ in non-pregnant Norwegian women [37]. In addition, a small Norwegian cross-sectional study detected inadequate UIC and iodine intake in elderly $(62 \mu \mathrm{g} / \mathrm{L})$, pregnant women $(84 \mu \mathrm{g} / \mathrm{L})$, non-pregnant women of childbearing age $(71 \mu \mathrm{g} / \mathrm{L})$, and in vegans
(46 $\mu \mathrm{g} / \mathrm{L})$ [38]. Due to introduction of iodine fortification of cow fodder in the 1950s and traditionally high intake of milk and dairy with subsequent high iodine concentrations, health authorities used to consider Norwegians to be iodine-replete [39]. The possible re-emergence of sub-optimal iodine levels in Norway may be linked to the recorded declining intake of both milk, dairy and seafood [40].

Concomitant with increased UIC after the lean-seafood intervention, we also observed increased urinary As levels and increased fasting plasma As and Se levels, similar to the findings by Molin et al. [15]. These results were expected, as lean-seafood will also provide other essential nutrients, such as $\mathrm{Se}$, as well as undesirable substances. Seafood consumption is a predictor of elevated urinary As in several population studies and may be used as a biomarker [41]. Seafood and cereals appear to be the most important contributor to adequate blood Se in adolescent Icelandic girls [42]. The relatively high content of As and other heavy metals, such as mercury (Hg), may be of concern. However, in lean-seafood the major As form is the arsenobetaine, considered to be non-toxic [43]. Several risk benefit evaluations of seafood have concluded that the beneficial effects of the essential nutrients in seafood outweighs potential harmful effects of undesirable substances, including mercury [44-46]. In this respect, the content of Se may be of particular importance. First, low Se intake is reported in several countries [47], and lean finfish species are good dietary sources for Se [16, 48]. Second, Se is also known to antagonize the toxic effects of heavy metals, including $\mathrm{Hg}$ [49], and a molar ratio of $\mathrm{Se}: \mathrm{Hg}$ above 1.0 is suggested to provide protection against $\mathrm{MeHg}$ toxicity in humans [50].

The strengths of this study include the crossover design and the balanced diets and accurate recordings of the seafood intake. The UIC measured in spot urine samples is the recommended method [4], but it reflects recent dietary intake and there is debated whether this is the best estimate of measuring iodine status. Thus, it is a strength that the participants consumed lean-seafood daily. Milk and dairy are major sources for iodine. Importantly, only very small amounts of dairy products were included in the non-seafood diet and all participants were instructed to not drink milk during any of the interventions.

This study has some limitations. The diets with $60 \%$ of dietary proteins from lean-seafood or non-seafood sources does not reflect a normal dietary protein intake for most people and the generalizability of our findings are thus limited. The comprehensive design limited the number of subjects willing to participate and led to a rather high drop-out (26\%). This was, however, accounted for in the power analysis. The power calculation was, however, not based on UIC as the primary endpoint, but on cardiovascular lipid risk markers. Further, only Caucasians were included. 
We conclude that 4 weeks of the lean-seafood intervention increased UIC from sub-optimal levels to adequate levels above $100 \mu \mathrm{g} / \mathrm{L}$. Iodized salt programmes have had a high impact globally, but several European countries have not followed this strategy and a sub-optimal iodine level is evident among subpopulations in Europe. Unlike iodized salt, iodine rich food items, such as lean-seafood will provide essential nutrients and undesirable substances, such as Se and As.

Acknowledgements Open Access funding provided by Institute of Marine Research. We thank the study participants and the staff at the laboratories.

Author contributions EKA and BL designed the study; EKA and BL conducted the research; JØ performed the statistical analyses; JØ, EKA, $\mathrm{BL}, \mathrm{EF}, \mathrm{LD}$ and LM contributed to data interpretation, JØ and LM wrote the first draft of the manuscript, JØ, EKA and LM had primary responsibility for the final content; all authors read and approved the final manuscript.

Funding This trial received financial support from the Research Council of Norway (200515/130), the Institute of Marine Research (previous National Institute of Nutrition and Seafood Research), Western Norway University of Applied Science (previous Bergen University College), University of Bergen. The sponsors had no influence of the execution of the study, the analysis, or the interpretation of the data.

Data availability Data (in anonymised form) used in the manuscript will be available upon request.

Code availability Statistical Package for the Social Sciences (SPSS ${ }^{\circledR}$ Statistics Version 26).

\section{Compliance with ethical standards}

Conflict of interest None of the authors have any conflict of interest to declare.

Ethics approval The study was registered at www.ClinicalTrials.gov (NCT01708681) (October 17, 2012) and performed in accordance with the ethical standards of the regional committee on human experimentation. The protocol, informed consent and advertisements were approved by the Regional Committee for Medical and Health Research Ethics West, Norway (Reference \# 2012/1084).

Consent to participate All subjects signed a written informed consent.

Consent for publication Not applicable.

Open Access This article is licensed under a Creative Commons Attribution 4.0 International License, which permits use, sharing, adaptation, distribution and reproduction in any medium or format, as long as you give appropriate credit to the original author(s) and the source, provide a link to the Creative Commons licence, and indicate if changes were made. The images or other third party material in this article are included in the article's Creative Commons licence, unless indicated otherwise in a credit line to the material. If material is not included in the article's Creative Commons licence and your intended use is not permitted by statutory regulation or exceeds the permitted use, you will need to obtain permission directly from the copyright holder. To view a copy of this licence, visit http://creativecommons.org/licenses/by/4.0/.

\section{References}

1. Levander OA, Whanger PD (2434S) Deliberations and evaluations of the approaches, endpoints and paradigms for selenium and iodine dietary recommendations. J Nutr 126(9 Suppl):2427S2434S. https://doi.org/10.1093/jn/126.suppl_9.2427S

2. Zimmermann MB, Andersson M (2012) Update on iodine status worldwide. Curr Opin Endocrinol Diabetes Obes 19(5):382-387. https://doi.org/10.1097/MED.0b013e328357271a

3. Abel MH, Korevaar TIM, Erlund I, Villanger GD, Caspersen IH, Arohonka P, Alexander J, Meltzer HM, Brantsaeter AL (2018) Iodine intake is associated with thyroid function in mild to moderately iodine deficient pregnant women. Thyroid 28(10):13591371. https://doi.org/10.1089/thy.2018.0305

4. World Health Organization (2007) Assessment of iodine deficiency disorders and monitoring their elimination. A guide for programme managers. https://apps.who.int/iris/bitstream/10665 /43781/1/9789241595827_eng.pdf.

5. Granfors M, Andersson M, Stinca S, Akerud H, Skalkidou A, Poromaa IS, Wikstrom AK, Nystrom HF (2015) Iodine deficiency in a study population of pregnant women in Sweden. Acta Obstet Gynecol Scand 94(11):1168-1174. https://doi. org/10.1111/aogs.12713

6. Andersen SL, Sorensen LK, Krejbjerg A, Moller M, Laurberg P (2013) Iodine deficiency in Danish pregnant women. Dan Med J 60(7):A4657

7. McMullan P, Hamill L, Doolan K, Hunter A, McCance D, Patterson C, Smyth P, Woodside JV, Mullan K (2019) Iodine deficiency among pregnant women living in Northern Ireland. Clin Endocrinol (Oxf). https://doi.org/10.1111/cen.14065

8. Unicef (2008) Sustainable elimination of iodine deficiency. https://data.unicef.org/resources/sustainable-elimination-ofiodine-deficiency/. Accessed 29 July 2020

9. Brantsaeter AL, Abel MH, Haugen M, Meltzer HM (2013) Risk of suboptimal iodine intake in pregnant Norwegian women. Nutrients 5(2):424-440. https://doi.org/10.3390/nu5020424

10. Dahl L, Johansson L, Julshamn K, Meltzer HM (2004) The iodine content of Norwegian foods and diets. Public Health Nutr 7(4):569-576. https://doi.org/10.1079/PHN2003554

11. Carlsen MH, Andersen LF, Dahl L, Norberg N, Hjartaker A (2018) New iodine food composition database and updated calculations of iodine intake among Norwegians. Nutrients 10(7):930. https://doi.org/10.3390/nu10070930

12. Nerhus I, Wik Markhus M, Nilsen BM, Oyen J, Maage A, Odegard ER, Midtbo LK, Frantzen S, Kogel T, Graff IE, Lie O, Dahl L, Kjellevold M (2018) Iodine content of six fish species, Norwegian dairy products and hen's egg. food. Nutr Res. https ://doi.org/10.29219/fnr.v62.1291

13. Gunnarsdottir I, Gustavsdottir AG, Steingrimsdottir L, Maage A, Johannesson AJ, Thorsdottir I (2013) Iodine status of pregnant women in a population changing from high to lower fish and milk consumption. Public Health Nutr 16(2):325-329. https ://doi.org/10.1017/S1368980012001358

14. Rasmussen LB, Ovesen L, Bulow I, Jorgensen T, Knudsen N, Laurberg P, Pertild H (2002) Dietary iodine intake and urinary iodine excretion in a Danish population: effect of geography, supplements and food choice. Br J Nutr 87(1):61-69. https:// doi.org/10.1079/bjn2001474

15. Molin M, Ulven SM, Dahl L, Lundebye AK, Holck M, Alexander J, Meltzer HM, Ydersbond TA (2017) Arsenic in seafood is associated with increased thyroid-stimulating hormone (TSH) in healthy volunteers-a randomized controlled trial. J Trace Elem Med Biol 44:1-7. https://doi.org/10.1016/j.jtemb.2017.05.004

16. Azad AM, Frantzen S, Bank MS, Nilsen BM, Duinker A, Madsen L, Maage A (2019) Effects of geography and species 
variation on selenium and mercury molar ratios in Northeast Atlantic marine fish communities. Sci Total Environ 652:14821496. https://doi.org/10.1016/j.scitotenv.2018.10.405

17. Khalili Tilami S, Sampels S (2018) Nutritional value of fish: lipids, proteins, vitamins, and minerals. Rev Fish Sci Aquac 26(2):243-253. https://doi.org/10.1080/23308249.2017.13991 04

18. Mohanty B, Mahanty A, Ganguly S, Sankar TV, Chakraborty K, Rangasamy A, Paul B, Sarma D, Mathew S, Asha KK, Behera B, Aftabuddin M, Debnath D, Vijayagopal P, Sridhar N, Akhtar MS, Sahi N, Mitra T, Banerjee S, Paria P, Das D, Das P, Vijayan KK, Laxmanan PT, Sharma AP (2014) Amino acid compositions of 27 food fishes and their importance in clinical nutrition. J Amino Acids 2014:269797. https://doi.org/10.1155/2014/269797

19. Aadland EK, Lavigne C, Graff IE, Eng O, Paquette M, Holthe A, Mellgren G, Jacques H, Liaset B (2015) Lean-seafood intake reduces cardiovascular lipid risk factors in healthy subjects: results from a randomized controlled trial with a crossover design. Am J Clin Nutr 102(3):582-592. https://doi.org/10.3945/ ajcn.115.112086

20. Wellek S, Blettner M (2012) Establishing equivalence or noninferiority in clinical trials: part 20 of a series on evaluation of scientific publications. Dtsch Arztebl Int 109(41):674-679. https ://doi.org/10.3238/arztebl.2012.0674

21. The Norwegian Directorate of Health. (2011) Dietary advice for the promotion of public health and the prevention of chronic disease. Directorate of Health Oslo (Norway)

22. Harris JA, Benedict FG (1918) A Biometric Study of Human Basal Metabolism. Proc Natl Acad Sci U S A 4(12):370-373. https://doi.org/10.1073/pnas.4.12.370

23. The Nordic Council of Ministers. Nordic nutrition recommandations: integrating nutrition and physical activity. (2004). vol 4th ed. The Nordic Council of Ministers Copenhagen (Denmark)

24. Dahl L, Meltzer HM, Opsahl JA, Julshamn K (2003) Iodine intake and status in two groups of Norwegians. Scan J Nutr 47(4):170-178

25. Sele V, Ornsrud R, Sloth JJ, Berntssen MHG, Amlund H (2018) Selenium and selenium species in feeds and muscle tissue of Atlantic salmon. J Trace Elem Med Biol 47:124-133. https://doi. org/10.1016/j.jtemb.2018.02.005

26. Julshamn K, Maage A, Norli HS, Grobecker KH, Jorhem L, Fecher P (2007) Determination of arsenic, cadmium, mercury, and lead by inductively coupled plasma/mass spectrometry in foods after pressure digestion: NMKL interlaboratory study. J AOAC Int 90(3):844-856

27. O'Kane SM, Pourshahidi LK, Mulhern MS, Strain JJ, Mackle EM, Koca D, Schomburg L, Hill S, O’Reilly J, Kmiotek D, Deitrich C, Bath SC, Yeates AJ (2018) Cow milk consumption increases iodine status in women of childbearing age in a randomized controlled trial. J Nutr 148(3):401-408. https://doi.org/10.1093/jn/ nxx043

28. Combet E, Ma ZF, Cousins F, Thompson B, Lean ME (2014) Low-level seaweed supplementation improves iodine status in iodine-insufficient women. Br J Nutr 112(5):753-761. https:// doi.org/10.1017/S0007114514001573

29. Herter-Aeberli I, Cherkaoui M, El Ansari N, Rohner R, Stinca S, Chabaa L, von Eckardstein A, Aboussad A, Zimmermann MB (2015) Iodine supplementation decreases hypercholesterolemia in iodine-deficient, overweight women: a randomized controlled trial. J Nutr 145(9):2067-2075. https://doi.org/10.3945/ jn.115.213439

30. Sigurdsson G, Franzson L (1998) Urinary excretion of iodine in and Icelandic population. Icelandic Med J 74:179-181

31. Laurberg P, Pedersen KM, Hreidarsson A, Sigfusson N, Iversen E, Knudsen PR (1998) Iodine intake and the pattern of thyroid disorders: a comparative epidemiological study of thyroid abnormalities in the elderly in Iceland and in Jutland. Denmark J Clin Endocrinol Metab 83(3):765-769. https://doi.org/10.1210/ jcem.83.3.4624

32. Gunnarsdottir I, Gunnarsdottir BE, Steingrimsdottir L, Maage A, Johannesson AJ, Thorsdottir I (2010) Iodine status of adolescent girls in a population changing from high to lower fish consumption. Eur J Clin Nutr 64(9):958-964. https://doi.org/10.1038/ ejcn.2010.100

33. Brantsaeter AL, Haugen M, Julshamn K, Alexander J, Meltzer HM (2009) Evaluation of urinary iodine excretion as a biomarker for intake of milk and dairy products in pregnant women in the Norwegian mother and child cohort study (MoBa). Eur J Clin Nutr 63(3):347-354. https://doi.org/10.1038/sj.ejcn.1602952

34. Nerhus I, Odland M, Kjellevold M, Midtbo LK, Markhus MW, Graff IE, Lie O, Kvestad I, Froyland L, Dahl L, Oyen J (2019) Iodine status in Norwegian preschool children and associations with dietary iodine sources: the FINS-KIDS study. Eur J Nutr 58(6):2219-2227. https://doi.org/10.1007/s00394-018-1768-0

35. Girelli ME, Coin P, Mian C, Nacamulli D, Zambonin L, Piccolo M, Vianello-Dri A, Gottardo F, Busnardo B (2004) Milk represents an important source of iodine in schoolchildren of the Veneto region. Italy J Endocrinol Invest 27(8):709-713. https:// doi.org/10.1007/BF03347510

36. Dahl L, Wik Markhus M, Sanchez PVR, Moe V, Smith L, Meltzer HM, Kjellevold M (2018) Iodine deficiency in a study population of Norwegian pregnant women-results from the little in Norway study (LiN). Nutrients 10(4):513. https://doi.org/10.3390/nu100 40513

37. Henjum S, Brantsaeter AL, Kurniasari A, Dahl L, Aadland EK, Gjengedal ELF, Birkeland S, Aakre I (2018) Suboptimal iodine status and low iodine knowledge in young Norwegian women. Nutrients 10(7):941. https://doi.org/10.3390/nu10070941

38. Brantsaeter AL, Knutsen HK, Johansen NC, Nyheim KA, Erlund I, Meltzer HM, Henjum S (2018) Inadequate iodine intake in population groups defined by age, life stage and vegetarian dietary practice in a Norwegian convenience sample. Nutrients 10(2):230. https://doi.org/10.3390/nu10020230

39. Nystrom HF, Brantsaeter AL, Erlund I, Gunnarsdottir I, Hulthen L, Laurberg P, Mattisson I, Rasmussen LB, Virtanen S, Meltzer HM (2016) Iodine status in the Nordic countries-past and present. Food Nutr Res 60:31969. https://doi.org/10.3402/fnr.v60.31969

40. Helsedirektoratet (2018) Utviklingen i norsk kosthold. vol IS-2759.

41. Taylor V, Goodale B, Raab A, Schwerdtle T, Reimer K, Conklin S, Karagas MR, Francesconi KA (2017) Human exposure to organic arsenic species from seafood. Sci Total Environ 580:266-282. https://doi.org/10.1016/j.scitotenv.2016.12.113

42. Gudmundsdottir EY, Gunnarsdottir I, Thorlacius A, Reykdal O, Gunnlaugsdottir H, Thorsdottir I, Steingrimsdottir L (2012) Blood selenium levels and contribution of food groups to selenium intake in adolescent girls in Iceland. Food Nutr Res. https://doi. org/10.3402/fnr.v56i0.18476

43. Molin M, Ulven SM, Meltzer HM, Alexander J (2015) Arsenic in the human food chain, biotransformation and toxicology-review focusing on seafood arsenic. J Trace Elem Med Biol 31:249-259. https://doi.org/10.1016/j.jtemb.2015.01.010

44. Chain EPoCitF, (2012) Scientific opinion on the risk for public health related to the presence of mercury and methylmercury in food. EFSA J 10(12):2985. https://doi.org/10.2903/j. efsa.2012.2985

45. VKM (2014) Benefit-risk assessment of fish and fish products in the Norwegian diet - an update. Scientific Opinion of the Scientific Steering Committee of the Norwegian Scientific Committee 
for Food Safety. Vitenskapskomiteen for mattrygghet, Oslo, Norway

46. Committee ES (2015) Statement on the benefits of fish/seafood consumption compared to the risks of methylmercury in fish/seafood. EFSA J 13(1):3982. https://doi.org/10.2903/j.efsa.2015.3982

47. Ullah H, Liu G, Yousaf B, Ali MU, Abbas Q, Munir MAM, Mian MM (2018) Developmental selenium exposure and health risk in daily foodstuffs: a systematic review and meta-analysis. Ecotoxicol Environ Saf 149:291-306. https://doi.org/10.1016/j.ecoen v.2017.11.056

48. Navarro-Alarcon M, Cabrera-Vique C (2008) Selenium in food and the human body: a review. Sci Total Environ 400(1-3):115141. https://doi.org/10.1016/j.scitotenv.2008.06.024
49. Rahman MM, Hossain KFB, Banik S, Sikder MT, Akter M, Bondad SEC, Rahaman MS, Hosokawa T, Saito T, Kurasaki M (2019) Selenium and zinc protections against metal-(loids)-induced toxicity and disease manifestations: a review. Ecotoxicol Environ Saf 168:146-163. https://doi.org/10.1016/j.ecoenv.2018.10.054

50. Ralston NVC, Ralston CR, Raymond LJ (2016) Selenium health benefit values: updated criteria for mercury risk assessments. Biol Trace Elem Res 171(2):262-269. https://doi.org/10.1007/s1201 $1-015-0516-z$ 